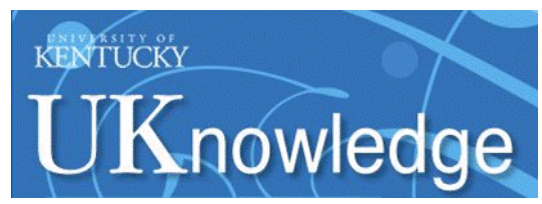

University of Kentucky

UKnowledge

\title{
$4-1981$
}

\section{Psychological Factors That Predict Reaction to Abortion}

\author{
D. T. Moseley \\ University of South Carolina \\ Diane R. Follingstad \\ University of South Carolina - Columbia \\ H. Harley \\ University of South Carolina \\ Robert V. Heckel \\ Unviersity of South Carolina
}

Follow this and additional works at: https://uknowledge.uky.edu/crvaw_facpub

Part of the Law and Gender Commons, and the Psychology Commons

Right click to open a feedback form in a new tab to let us know how this document benefits you.

\section{Repository Citation}

Moseley, D. T.; Follingstad, Diane R.; Harley, H.; and Heckel, Robert V., "Psychological Factors That Predict Reaction to Abortion" (1981). CRVAW Faculty Journal Articles. 62.

https://uknowledge.uky.edu/crvaw_facpub/62

This Article is brought to you for free and open access by the Center for Research on Violence Against Women at UKnowledge. It has been accepted for inclusion in CRVAW Faculty Journal Articles by an authorized administrator of UKnowledge. For more information, please contact UKnowledge@lsv.uky.edu. 


\section{Psychological Factors That Predict Reaction to Abortion}

\section{Digital Object Identifier (DOI)}

http://dx.doi.org/10.1002/1097-4679(198104)37:2<276::AID-JCLP2270370208>3.0.C0;2-H

\section{Notes/Citation Information}

Dr. Diane Follingstad had not been a faculty member of the University of Kentucky at the publication time. 


\title{
PSYCHOLOGICAL FACTORS THAT PREDICT REACTION TO ABORTION
}

\author{
D. T. MOSELEY, D. R. FOLlingstad AND H. HARLEY \\ University of South Carolina \\ R. V. HECKEL \\ Social Problems Research Institute \\ Universily of South Carolina
}

\begin{abstract}
Investigated demographic and psychological factors related to positive or negative reactions to legal abortions performed during the first trimester of pregnancy in 62 females in an urban southern community. Results suggest that the social context and the degree of support from a series of significant persons rather than demographic variables were most predictive of a positive reaction.
\end{abstract}

The right of women to terminate pregnancy, legally approved in January 1973 , is now a reality for an increasing number of women. It is estimated that more than a million women obtain therapeutic abortions each year. That number is expected to increase significantly unless restrictions are imposed on federal support.

Despite a voluminous literature, little is known about psychological factors that influence reactions to legal abortion. The majority of studies are not relevant because most address conditions and options that existed prior to legalization or were conducted in a sociocultural milieu that precludes any precise extrapolation of data for our society (Smith, 1973).

In early research on abortion, one consistent finding was that women with psychological problems prior to an abortion continue to have difficulty after the procedure. Most studies either failed to distinguish between spontaneous, illegal and therapeutic abortion, or failed to specify the particular psychological, social and cultural variables and their impact. Recent studies on legal and therapeutic abortions report a consistently lower incidence of emotional sequelae than did previous literature (Bracken, Hachamovitch \& Grossman, 1974; Osofsky \& Osofsky, 1972; Payne, Kravitz, \& Notman, 1976; Robbins, 1979; Smith, 1973).

In general, reports indicate that severe emotional reactions are rare except when the pre-abortion adjustment is poor. Most suggest that $75 \%$ to $95 \%$ of those who sought abortions were later content with this decision.

The issue of legalized abortion is still controversial and in need of extensive research. The focus of the present study is to determine the value of demographic variables, social variables, and two psychological tests (Rotter's Locus of Control, Multiple Affect Adjective Check List) in predicting reactions to legal abortion.

\section{METHOD}

Structured questionnaires were administered to women who obtained legal elective abortion in an urban southern area. A pretest was administered to the $S$ s when they entered the clinic prior to the standard pre-abortion counseling. The post-abortion questionnaire was given in the recovery room prior to discharge.

\section{Subjects}

Ss were 62 women ( 40 white, 22 black), who ranged in age from 14 to 35 years $(\mathrm{MA}=22.0$ ). All were 12 weeks or less from their last menstrual periods. Ss were told that information was being gathered to understand better the experiences of women who were obtaining abortions. Confidentiality and anonymity were stressed. All Ss underwent suction curretage, the simplest procedure for early pregnancy termination on an outpatient basis. All were required to remain ap- 
proximately 5 hours and were given individual psychological counseling only upon request or if they were observed to be experiencing stress (i.e., crying).

\section{Measures}

The following measures were administered: Multiple Affective Adjective Check List (MAACL) scales-anxiety, depression, and hostility-(Zuckerman \& Lubin, 1965) (given pre and post); Rotter (1966) Locus of Control Scale (pre); an 18-item questionnaire, the Personal Reaction Questionnaire (PRQ) (Follingstad, Note 1), which differentiates between the traditional and the liberated female in terms of perceived values and role expectations. In addition, 19 questions were administered that related to interpersonal experiences and attitudes with regard to abortion.

Data were analyzed using the Pearson $r$ on all measures. Pre and post scores on the MAACL (hostility, anxiety, depression) were analyzed by $t$ tests.

\section{RESULTS}

Differences in psychological reactions and attitudes were not found on the basis of age (range 14 to 35 ), though older women were found to have a higher number of children $(r=.25, p<.05)$ and attained a higher level of education $(r=.24, p<.05)$. Greater numbers of children was a significant predictor of more positive attitudes toward abortion. Women with larger numbers of children made the decision for abortion on their own $(r=.23, p<.05)$ and had a lower level of pre-abortion bostility $(r=.29, p<.05)$. Similarly, women with higher levels of education made the decision on their own $(r=.34, p<.01)$ and had lower levels of pre-abortion hostility $(r=-.33, p<.01)$ than women with lower levels of education.

Blacks reported less effective birth control methods for this pregnancy ( $r$ $=.27, p<.05$ ) and reported impregnation more often by a significant other (i.e., fiancé, husband) $(r=.27, p<.05)$ than whites. Blacks scored lower on preabortion anxiety $(r=-.24, p<.05)$ and post-abortion hostility $(r=-.24, p$ $<.05)$, but had a more difficult decision than whites on whether or not to abort $(r=.41, p<.001)$. White women scored more external on locus of control than black women $(r=-.28, p<.05)$, an unexpected finding.

Attitudes on feminine issues using PRQ revealed that higher traditional values were related to higher emotional involvement with the partner in conception $(r=.28, p<.05)$. A second unexpected finding was tbac more liberated women experienced greater post-abortion anxiety $(r=.26, p<.05)$ and depression $(r=.25, p<.05)$.

The woman's relationship with her partner in conception was confirmed as a crucial determinant in her post-abortion adjustment. When the partner in conception was a casual acquaintance, the decision to abort was easier than when the partner had been a husband or fiancé $(r=.27, p<.05)$. Women impregnated by a highly significant partner tended to have closer relationships with parents $(r=.24, p<.05)$ and lower levels of post-abortion anxiety $(r=.25, p<.05)$ than those involved with low emotional commitment. Perceived support from the partner resulted in lower levels of pre-abortion anxiety $(r=.22, p<.05)$. Opposition to abortion from the partner was offset by closer relationships and support from the parents $(r=-.36, p<.01)$. Women with negative feelings toward their partners were found to have higher levels of pre-abortion anxiety $(r=.27, p<.05)$, hostility $(r=.42, p<.001)$, and depression $(r=.31, p<.01)$, and post-abortion hostility $(r=.27, p<.05)$.

Analysis of the abortion decision revealed several significant findings. Women who made their decision alone had an easier time $(r=.27, p<.05)$, but had higher levels of pre-abortion depression $(r=.37, p<.01)$ and post-abortion depression $(r=.40, p<.001)$ than those who were assisted in the decision by their sexual partner. Women who reported greater ease in deciding to abort had greater levels 
of pre-abortion hostility $(r=.22, p<.05)$ and post-abortion hostility $(r=.23$, $p<.05$ ). Ss who reported greater decision difficulty had higher levels of opposition to abortion from both the partner in conception $(r=.33, p<.01)$. Locus of control scores indicated that high externals decided to abort with less difficulty than internally controlled women $(r=.49, p<.001)$.

Parents exerted considerable influence in affecting the emotional outcome of the abortion. Because the mean age of the $S s$ was 22.0 , parental influence can be viewed as a viable force in Ss' lives. Increased opposition from the parents correlaetd with greater amounts of post-abortion hostility $(r=.23, p<.05)$. Parental opposition resulted in greater perceived distance from them $\langle r=.47$, $p<.001)$. As a result, these women were more influenced by others $(r=.28, p$ $<.05)$.

Peer groups also were found to be influential. If opposition was encountered from friends, Ss reported more difficulty in deciding on abortion $(r=.31, p<.01)$ and greater amounts of pre-abortion depression $(r=.31, p<.01)$ than when friends were supportive.

Data from the abortion questionnaire revealed the following: To the question as to whether they would have obtained an illegal abortion, $25 \%$ said yes, $42 \%$ reported no, and $33 \%$ of the $\mathrm{Ss}$ were uncertain. As to a future desire for children, $65 \%$ indicated yes, $13 \%$ said no, and $23 \%$ were uncertain. In this population, $60 \%$ had no children, $21 \%$ had one child, $8 \%$ had two and $10 \%$ had three or more. Fifty percent of the women reported their regular method of birth control was the pill, $6.5 \%$ used an I.U.D., $4.5 \%$ used foam, and $35.5 \%$ used no birth control techniques. Seventy-three percent reported that at the time of this pregnancy they were not utilizing any form of contraception.

The marital status of the $\mathrm{Ss}$ was single $(73 \%)$, married $(18 \%)$, separated or divorced $(8 \%)$. The partners in conception: $43 \%$ were regular boyfriends, $25 \%$ fiances, $24 \%$ husbands, and $7 \%$ by a casual boyfriend.

When asked to whom they usually take their problems, $55 \%$ indicated their male significant other (i.e., husband, boyfriend), $25 \%$ said their parents, and $21 \%$ reported taking their problems to their friends.

Most women who were seeking an abortion were referred to the clinic by a physician $(35.5 \%)$ or health clinic $(16.1 \%)$, with $14.5 \%$ having been made aware by the media. Most reported seeking an abortion in order to continue educational or occupational plans $(48 \%)$, finances $(19.4 \%)$, unmarried $(11.3 \%)$, and a lack of desire to have children $(11.3 \%)$. When asked if they had ever consulted a psychologist or psychiatrist, $82.3 \%$ responded negatively.

The MAACL provided an index from which the abortion experience can be viewed empirically. Pre-abortion data revealed heightened levels of anxiety ( $M$ $=12.91)$, hostility $(M=10.06)$, and depression $(M=19.80)$, all much higher than levels for normals reported by Zuckerman and Lubin (1965)-anxiety, $M$ $=6.70$; hostility, $M=6.70$; depression, $M=11.10$. Significant decreases in pre- and post-abortion anxiety and depression vs. post-abortion anxiety $(t=7.27$, $p<.001)$ and depression $(t=3.17, p<.01)$ were found. Pre-/post-hostility changes were not significant.

The results from the present study confirm many of the findings from previous studies in addition to revealing potential negative reactions to abortion.

Comparison of the abortion experience between blacks and whites revealed that blacks scored significantly lower on pretesting anxiety. The finding that blacks experience greater crisis in their decision may be related to Blacks valuing having children more highly than whites, with abortion a less desirable alternative. Because blacks were impregnated most often by a husband or fiancé and often had failed to use contraceptive devices, it is possible that many either wanted to become pregnant or viewed it with less concern.

The finding that white women were more external than blacks on Rotter's Locus of Control Scale suggests that only the emancipated black female, one 
who is more internal, seeks abortion. There also may be a trend for "internal" white females today to go against society and have a baby when single. This LOC finding runs counter to earlier researches. Liberated women also tended to devalue the significance of the partner in conception. Whether these findings represent personal traits typlified by those active in the Women's Movement is unclear.

Overall, the findings strongly confirm that the most important determinant of the women's psychological reaction to abortion is the perceived amount of support from the women's significant others (partner in conception, parents, and friends). Support from any one of these is enough to off set opposition from another. Opposition encountered in the decision to abort results in statistically higher levels of anxiety, depression, and hostility.

Women who made their own decision to abort scored lower on the degree of difficulty in spite of the fact that the scores were higher on pre- and post-abortion hostility. A contradiction arises from the fact that if the decision is relatively easy, why the high level of hostility? It may be difficult simultaneously to feel guilt and hostility, and hostility is considered to be a major defensive response to guilt.

This study has raised many questions and provided suggestions for additional research, a necessity for a full understanding of the impact of elective, legal abortion on women.

\section{REFERENCE Note}

1. Founnastad, D. Personal reaction questionnaire. Unpublished test, University of South Carolina, 1976.

\section{REFERENCES}

Bracken, M. B., Hachamovitch, M., \& Grossman, G. The decision to abort and psychological sequelae. American Journal of Obatretrics and Gynecology, 1974, 117, 154-159.

Osorskr, J., \& Osorsky, H. The psychological reactions of patients to legalized abortion. American Journal of Orthopsychiatry, 1972, 426, 48-60.

Parne, E. D., Kratitz, A. R., \& Notman, M. T. Outcome following therapeutic abortion. Archives of General Psychiatry, 1976, 39, 725-733.

Robrins, J. M. Objective versus subjective responses to abortion. Journal of Consulting and Clinical Psychology, 1979, 47, 994-995.

ROTTER, J. B. Generalized expectancies for internal versus external control of reinforcement. Psychological Monographs, 1966, 80(1).

Sump, E. A follow-up study of women who request abortion. A merican Journal of Orthopsychiatry, $1973,49,235-237$.

Zocrorman, M., \& Lobin, B. Manual for the Multiple Affect Adjective Check List. Educational and Industrial Testing Service, 1965. 
Copyright of Journal of Clinical Psychology is the property of John Wiley \& Sons Inc. and its content may not be copied or emailed to multiple sites or posted to a listserv without the copyright holder's express written permission. However, users may print, download, or email articles for individual use. 